 \\ UF $\mid$ FLORIDIDA \\ IFAS Extension
}

\section{Florida's Introduced Birds: Monk Parakeet (Myiopsitta monachus) 1}

Steve A. Johnson and Sam Logue ${ }^{2}$

Many non-native birds have been introduced in Florida-perhaps as many as 200 species! Of these, at least 14 introduced species are considered established, according to various authorities, and some are now considered invasive and could have serious impacts in Florida. This fact sheet introduces the Monk Parakeet, and is one of a series of fact sheets about Florida's established non-native birds and their impacts on our native ecosystems, economy, and the quality of life of Floridians. For more information on Florida's introduced birds, how they got here, and the problems they cause, read "Florida's Introduced Birds: An Overview," http://edis.ifas.ufl.edu/UW297 and the other fact sheets in this series,

http://edis.ifas.ufl.edu/ topic_series_floridas_introduced_birds.

\section{Species Description}

The Monk Parakeet (Myiopsitta monachus) is a member of the parrot family (Psittacidae). Unlike most members of the parrot family, which eat mostly seeds and nest in cavities (such as tree holes), Monk
Parakeets also eat a variety of fruits and are the only parrot species that builds nests out of sticks.

Monk Parakeets are small to medium-sized parrots, approximately 12 inches long $(29 \mathrm{~cm})$ with a wingspan of 20 inches $(53 \mathrm{~cm})$ and weigh $3-4$ ounces (90-120 g). These small parrots are brightly colored (Fig. 1); their thick beaks are yellow-brown, their backs (including the backs of their heads) and tails are bright green, and their flight feathers are blue to bluish-black. In contrast, their faces, throats, chests, and legs are pale gray. The plumage of Monk Parakeets is similar in both sexes throughout the year; juveniles may be brighter green. Monk Parakeets are noisy birds whose calls have been described as metallic, rasping squawks and screams.

\section{Similar Species}

Monk Parakeets do not closely resemble any native Florida birds but are similar in appearance to several introduced parrots. Two closely-related introduced parakeets, the White-winged (Brotogeris versicolurus; formerly Canary-winged) and Yellow-chevroned (B. chiriri) Parakeets (Fig. 2) are

1. This document is WEC257, of the Department of Wildlife Ecology and Conservation, University of Florida / IFAS. This document is one of several documents in the series entitled "Florida's Introduced Birds," published by Dr. Steve A. Johnson. Visit the University of Florida's EDIS Web site at http://edis.ifas.ufl.edu. First published June 2009.

2. Steve A. Johnson, assistant professor and Extension specialist, Department of Wildlife Ecology and Conservation and Gulf Coast Research and Education Center, University of Florida/ IFAS - Plant City Center, 1200 North Park Road, Plant City, FL 33563; Sam Logue, student, Gulf Coast Research and Education Center, University of Florida/ IFAS - Plant City Center, 1200 North Park Road, Plant City, FL 33563.

The Institute of Food and Agricultural Sciences (IFAS) is an Equal Opportunity Institution authorized to provide research, educational information and other services only to individuals and institutions that function with non-discrimination with respect to race, creed, color, religion, age, disability, sex, sexual orientation, marital status, national origin, political opinions or affiliations. U.S. Department of Agriculture, Cooperative Extension Service, University of Florida, IFAS, Florida A. \& M. University Cooperative Extension Program, and Boards of County Commissioners Cooperating. Millie Ferrer, Interim Dean 
highly similar in appearance to the Monk Parakeet, but are slightly smaller, with green faces and chests and an obvious yellow band on the outer surfaces of their wings. The introduced Black-hooded Parakeet or Nanday Conure (Nandayus nenday; Fig. 3) is also

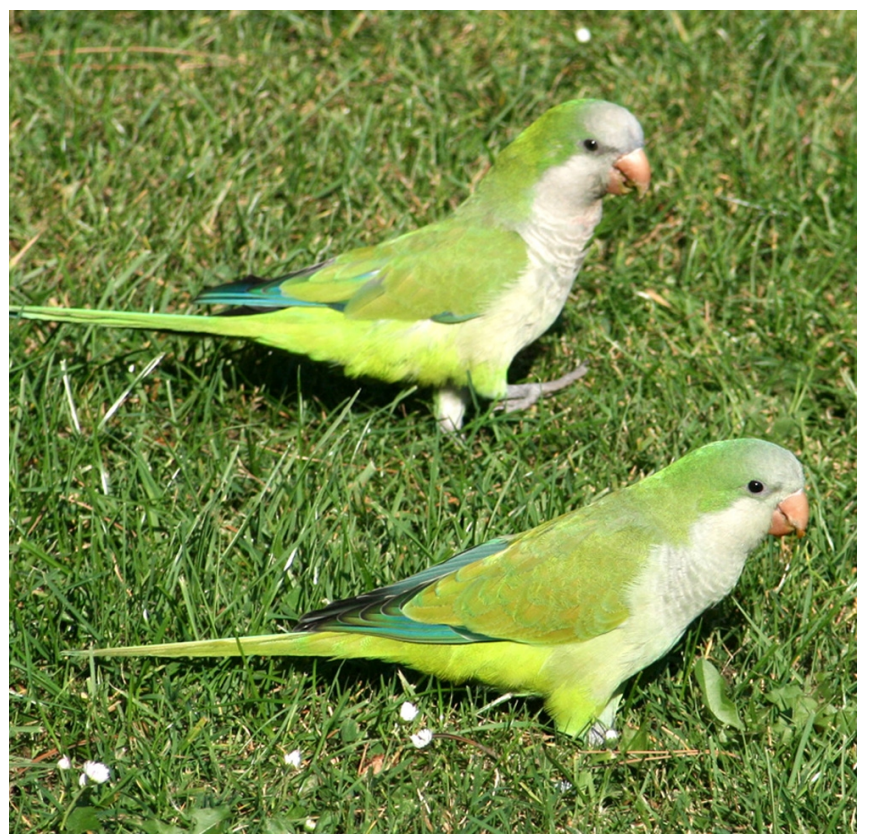

Figure 1. Monk Parakeets (Myiopsitta monachus) are brightly colored small to medium-sized parrots. Credits: Szilas, Wikimedia Project, 2007

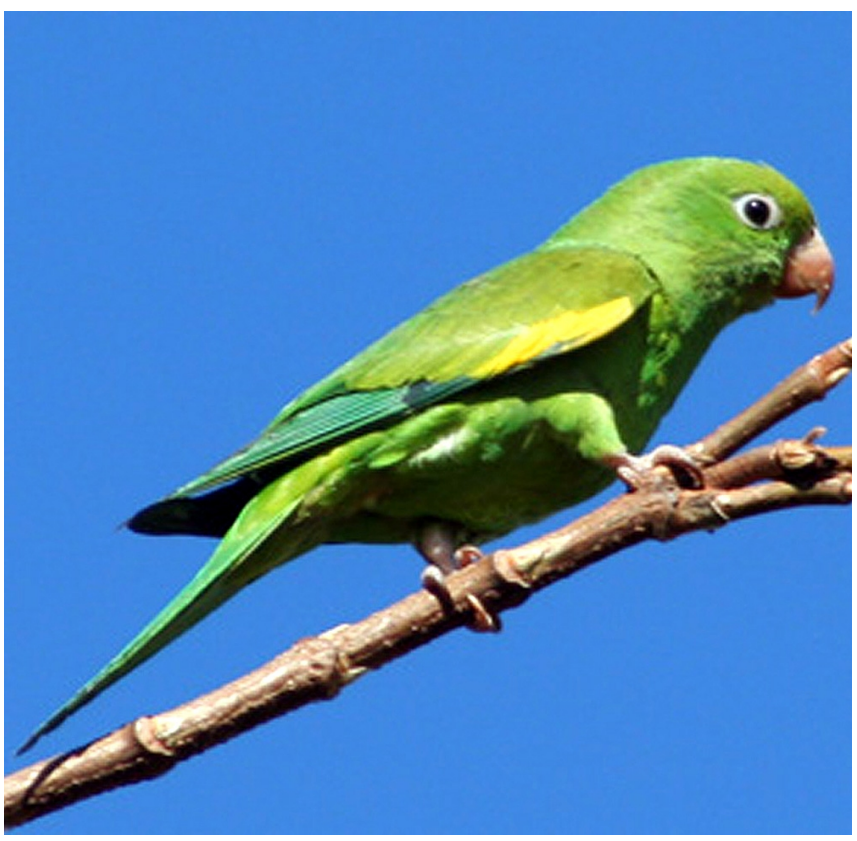

Figure 2. Two introduced parakeets, the White-winged (Brotogeris versicolurus) and Yellow-chevroned (B. chiriri, shown here) species, are highly similar in appearance to Monk Parakeets, but can be easily distinguished by their green chests and faces and the yellow band on their wings. Credits: Irene Nobrega, Wikimedia Project, 2008 similar in appearance, but has a distinctively black head. Monk Parakeets may also be confused with Budgerigars or "Budgies" (Melopsittacus undulatus, Fig. 4), but these small parrots lack the gray face and chest, and are only half the size of Monk Parakeets.

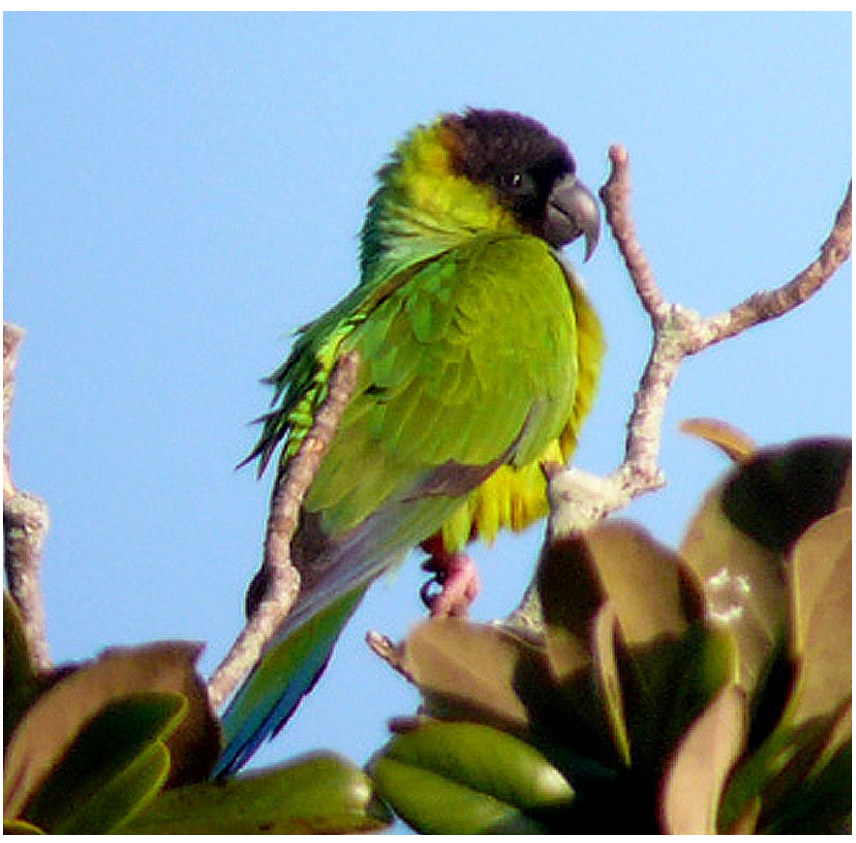

Figure 3. The introduced Nanday Conure (Nandayus nenday, also known as the Black-hooded Parakeet) is also highly similar in appearance to the Monk Parakeet, but has a distinctively black head. Credits: Jeff Bouton, Leica Sport Optics, 2007

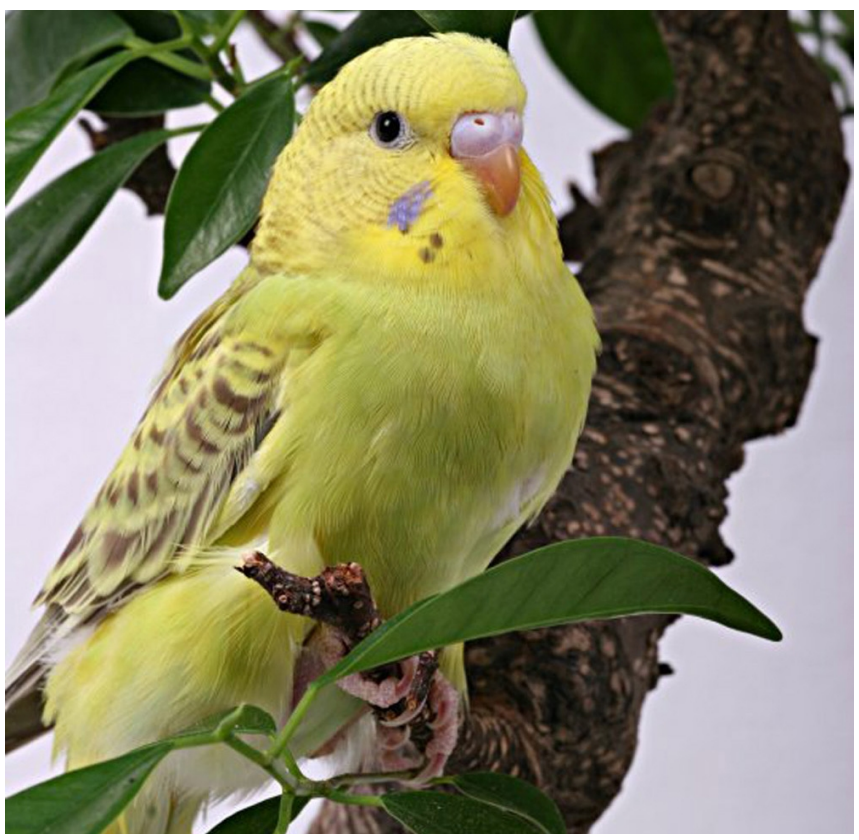

Figure 4. Budgerigars or "Budgies" (Melopsittacus undulatus) are somewhat similar in appearance to Monk Parakeets, but lack the gray face and chest and are only half the size of Monk Parakeets. Credits: Sebastian Ritter, Wikimedia Project, 2006 


\section{Native Range and Habitats}

Monk Parakeets are native to temperate and subtropical regions of South America, where they inhabit savannahs and woodlands at low elevations. Widespread tree-planting in parts of South America has allowed these birds to expand their native range to include the grasslands of the Pampas that previously did not have trees for roosting or nesting.

\section{Mode of introduction}

In the 1960s, Monk Parakeets became extremely popular in the pet trade, and by the end of the decade United States' imports had increased to more than 16,000 Monk Parakeets per year! Reports of free-ranging individuals date back to the 1960s, when wild Monk Parakeets were reported from cities across the country. Many of these birds are believed to have escaped from damaged shipping crates, whereas others accidentally escaped from their owners or from zoos, or were intentionally released. Monk Parakeets were first documented nesting in Florida in 1969.

\section{Introduced Range and Habitats}

In the contiguous United States, Monk Parakeet populations have been documented in at least 14 states. However, populations often disappear as rapidly as they arrive, and the introduced range of this species (Fig. 5) is highly dynamic. In the United States, the greatest concentration of Monk Parakeets is found in the subtropical regions of peninsular Florida and southeastern Texas. However, persistent, thriving populations are also found in New York City, Chicago, and Connecticut. In contrast to the natural habitats used in their native range, introduced Monk Parakeets are found predominantly in urban/suburban areas. Monk Parakeets have also been introduced in Quebec, Canada near Montreal, and in the Bahamas, Belgium, Italy, England, and Spain, where they are present in large numbers.

\section{Ecology}

The diet of Monk Parakeets is variable, depending on local availability of seeds, fruits,

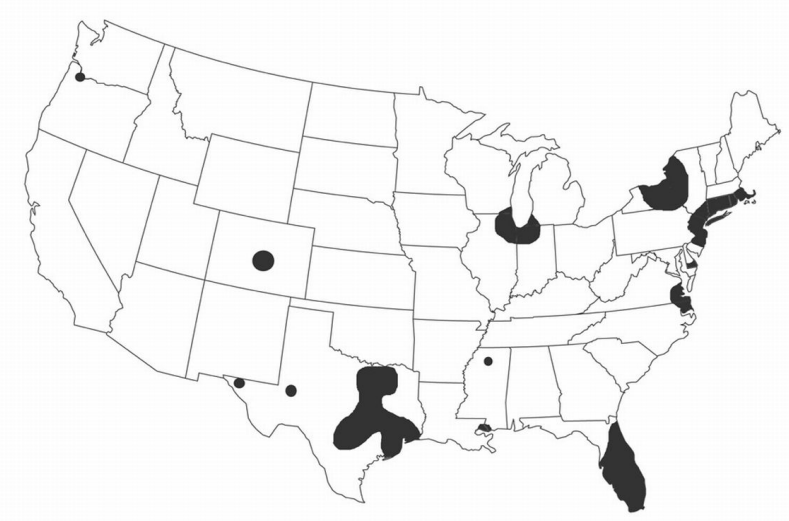

Figure 5. Approximate United States range of the Monk Parakeet (Myiopsitta monachus). Credits: Monica McGarrity, University of Florida, 2009

berries, nuts, flowers, and leaf buds. Throughout their introduced range, Monk Parakeets obtain much of their food from bird feeders. They also eat grass seeds, acorns, pine nuts, cedar berries, palm fruits, dandelions, apples, or bird seed, and may forage in agricultural areas on corn, wheat, and other seeds. On occasion, Monk Parakeets will prey on insects and other small invertebrates. They will sometimes forage in flocks, while "sentinels" perch on high vantage points to keep a lookout for predators.

Monk Parakeets nest in natural or man-made sites. In Florida, they commonly nest in tall melaleuca (also introduced) or palm trees, or more commonly on radio towers, light poles, and electrical utility structures. Monk parakeets are unique among parrots, in that they are the only parrot that builds nests out of sticks (Fig. 6) rather than nesting in cavities. They select nest material from whatever is readily available nearby, which in Florida often consists of landscape plants such as bougainvillea. Monk Parakeets are highly social and often build large communal nests made up of many individual chambers, each of which houses a pair of birds.

\section{Ecological Impacts}

The impacts of introduced Monk Parakeets on native flora and fauna are likely minimal. It is unlikely that Monk Parakeets compete with native birds for nesting space because they prefer to nest on man-made structures in urban/suburban areas. Similarly, Monk Parakeets obtain most of their food 


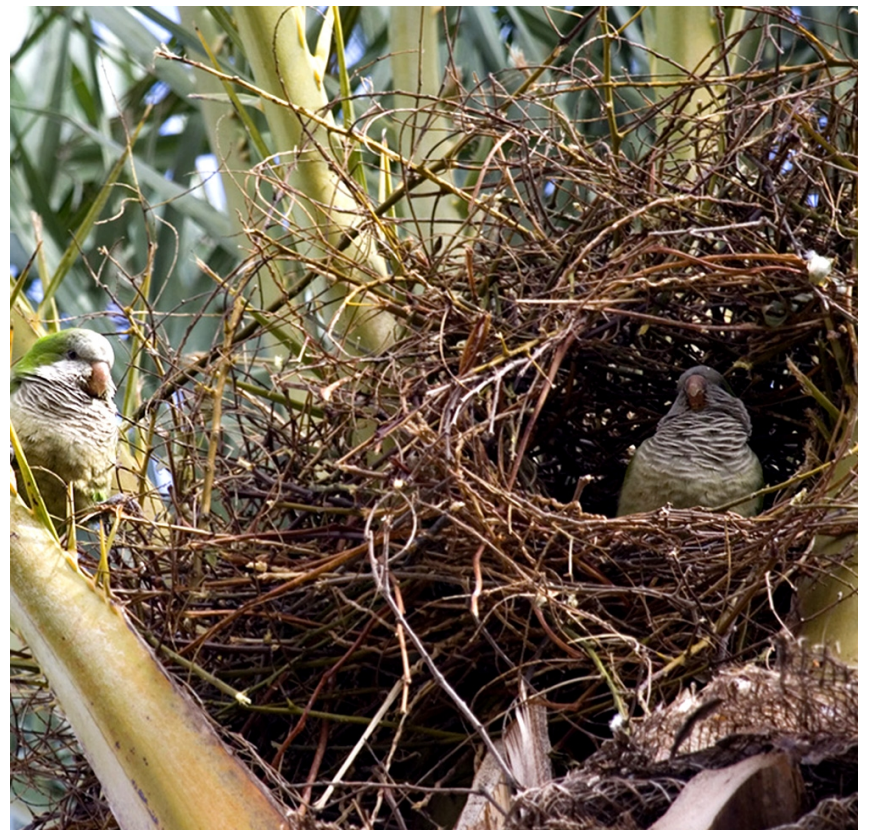

Figure 6. Monk Parakeets are the only parrots that build nests out of sticks instead of nesting in cavities. They prefer to build these nests in tall trees (like this palm) or on manmade structures. Credits: J. Dietrich, Wikimedia Project, 2008

from bird feeders, and probably compete only indirectly with native birds for food at these feeders.

\section{Impacts on People and Pets}

In many urbanized areas, Monk Parakeets are a huge nuisance, forming large, noisy flocks that can be heard for great distances. In south Florida, Monk Parakeets prefer to nest on light poles and on electric utility structures such as transmission line towers, substations, and distribution line poles (Fig. 7). When they become wet, these large nests can cause short-circuits, disrupt power, and damage equipment, and removal of Monk Parakeet nests can be difficult, dangerous, and costly.

Monk Parakeets also have the potential to become significant agricultural pests, which could greatly impact Floridians and our economy. In South America, Monk Parakeets are known to wreak havoc on agricultural crops-in the mid-1970s these birds were responsible for destruction of up to $45 \%$ of some crops. Such severe impacts have not been seen in Florida, although research suggests that these invasive birds may cause significant damage to some specialty tropical fruits. The lack of major agricultural impacts may be due to their preference for urbanized areas, and range expansion into agricultural areas could have devastating consequences.

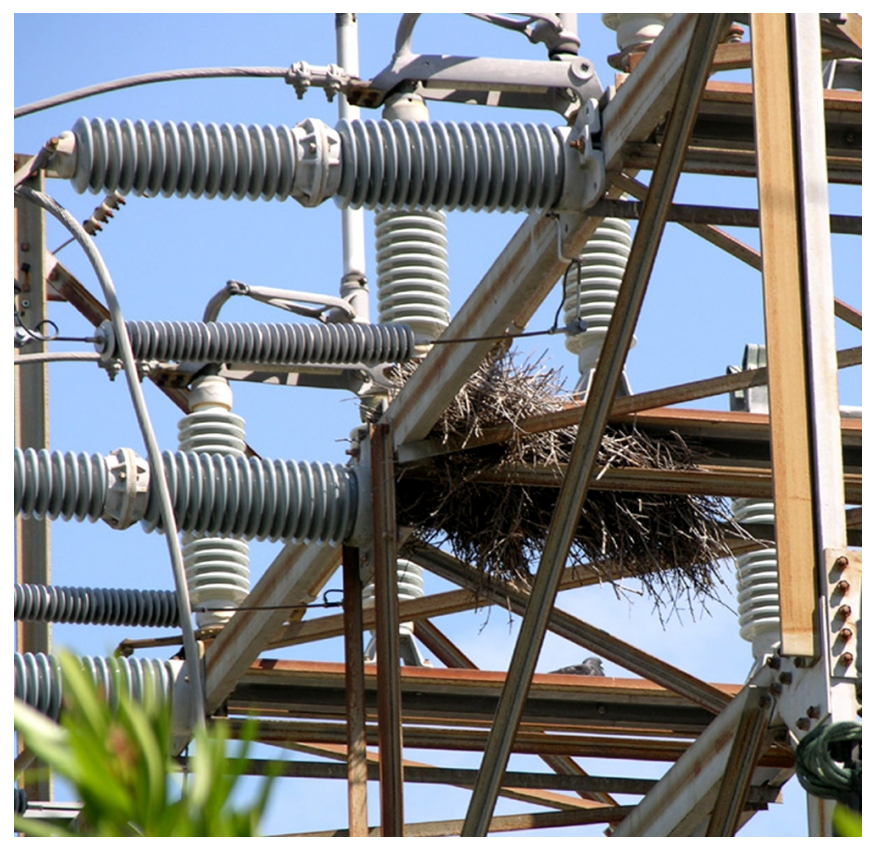

Figure 7. Monk Parakeets often nest on electrical utility structures, like this substation. When their nests become wet, they can cause short-circuit and power disruption, and are difficult and dangerous to remove. Credits: Steve A. Johnson, University of Florida, 2008

\section{Solutions}

In urban areas where Monk Parakeets (and other introduced parrots) are present, you can try to limit the food resources available to them. In northern parts of their introduced range, Monk Parakeets feed exclusively at bird feeders during the coldest months. Although feeders may not be the only food source available to Monk Parakeets in Florida, even in the coldest months, removal of feeders may make your yard less attractive to these birds. Removal of fruit-producing ornamental plants (especially invasive plants like Brazilian pepper) may also reduce the food resources available to Monk Parakeets and will help prevent these birds from spreading the seeds of invasive plants to new locations. If Monk

Parakeets nest in your yard, you should remove nests immediately, or call a nuisance wildlife professional for assistance — a professional may also be able to trap and remove some of the birds. Many electric utility companies in Florida are involved in ongoing research to develop deterrents, trapping methods, and 
other techniques that may also help to reduce the costly damages caused by these birds.

\section{How You Can Help}

You can help to alleviate the growing numbers of non-native bird species in Florida by being a responsible and educated pet owner. Never set any pet free outside! You can also help by learning more about invasive plants and animals and their impacts on Florida's natural environment, and by educating others. For more information on Florida's introduced birds and how you can help, read "Florida's Introduced Birds: An Overview" (http://edis.ifas.ufl.edu/uw297), and check out the Additional Resources listed below.

\section{Additional Resources}

There are a variety of online guides, books and other publications that we recommend for additional information on Florida's native and non-native birds.

\section{Books and Scientific Publications}

Avery, M. L., and M. P. Moulton, "Florida's non-native avifauna," Managing Vertebrate Invasive Species: Proceedings of an International Symposium (G. W. Witmer, W. C. Pitt, K. A. Fagerstone, Eds.). (Fort Collins, CO: USDA/APHIS/WS, National Wildlife Research Center, 2007).

Avery, M. L., E. C. Greiner, J. R. Lindsay, J. R. Newman, and S. Pruett-Jones, "Monk parakeet management at electric utility facilities in south Florida," Proceedings: Vertebrate Pest Conference 20 (2002):140-145.

Avery, M. L., C. A. Yoder, and E. A. Tillman, "Diazacon inhibits reproduction in invasive Monk Parakeet populations," Journal of Wildlife Management 72 (2008): 1449-1452.

Alsop, Fred J., Smithsonian Handbooks: Birds of North America - Eastern Region. (New York: DK Publishing, Inc., 2001).

Bull, J., and J. Farrand, Jr., The Audubon Society Field Guide to North American Birds. (New York: Alfred A. Knopf, 1977).
Kale, H. W. II, and D. S. Maehr, Florida's Birds.

(Sarasota: Pineapple Press, Inc., 1990).

Peterson, R. T., Peterson Field Guides, Eastern Birds. (Boston: Houghton Mifflin Co., 1980).

Pranty, B., A Birder's Guide to Florida. (Colorado Springs: American Birding Association, 1996).

Robbins, C. S., B. Bruun, H. S. Zim, and A. Singer, A Golden Guide to Field Identification: Birds of North America. (New York: Golden Press, 1983).

Sibley, D. A., The Sibley Field Guide to Birds of Eastern North America. (New York: Knopf, 2003).

Spreyer, M. F., and E. H. Bucher, "Monk Parakeet (Myiopsitta monachus)," in The Birds of North America Online (A. Poole, Ed.). (Ithaca: Cornell Lab of Ornithology, 1993). Retrieved from the Birds of North America Online:

http://bna.birds.cornell.edu/bna/species/322

Tillman, E. A., A. C. Genchi, J. R. Lindsay, J. R. Newman, and M. L. Avery, "Evaluation of trapping to reduce monk parakeet populations at electric utility facilities," Proceedings of the Vertebrate Pest Conference 21 (2004):126-129.

Tillman, E. A., A. Van Doorn, and M. L. Avery, "Bird damage to tropical fruit in south Florida," Proceedings of the Wildlife Damage Management Conference 9 (2001): 47-59.

Woolfenden, G. E., W. B. Robertson, Jr., and J. A. Cox, The Breeding Birds of Florida. (Florida Ornithological Society Special Publication 7, 2006)

\section{Online}

USDA National Invasive Species Information Center (NISIC)

http://www.invasivespeciesinfo.gov/index.shtml

AgNIC Wildlife Damage Management-USDA Wildlife Services National Wildlife Research Center \& Colorado State University Libraries-Monk Parakeet http://lib.colostate.edu/research/agnic/invspecies/ parakeets.html 
Florida Fish and Wildlife Conservation Commission

Non-Native Wildlife

http://myfwc.com/nonnatives/index.htm—click on

"Birds"

Florida Fish and Wildlife Conservation Commission

Breeding Bird

Atlashttp://myfwc.com/bba/default.htm

World Conservation Union, Species Survival Group, Invasive Species Specialist Group

http://www.issg.org—click on "Global Invasive

Species Database", search for species

Cornell Lab of Ornithology "All About Birds"

http://www.birds.cornell.edu/AllAboutBirds—click

on "Bird Guide", search for species

United States Geological Survey, Patuxent Wildlife

Research Center, Bird Identification

http://www.mbr-pwrc.usgs.gov—click on "Bird

Identification InfoCenter"

Institute for Biological Invasions, Department of

Ecology and Evolutionary Biology, University of

Tennessee-Monk Parakeet

http://invasions.bio.utk.edu/invaders/monk.html 